\title{
Synthesis of nanocrystalline $\mathrm{SnO}_{2}$ powder at $100^{\circ} \mathrm{C}$
}

\author{
SANJAY R DHAGE, S P GAIKWAD, VIOLET SAMUEL ${ }^{\dagger}$ and V RAVI* \\ Physical and Materials Chemistry Division, ${ }^{\dagger}$ Catalysis Division, National Chemical Laboratory, Pune 411008 , India
}

MS received 9 January 2004

\begin{abstract}
A simple gel to crystal conversion route has been followed for the preparation of nanocrystalline $\mathrm{SnO}_{2}$ at $80-100^{\circ} \mathrm{C}$ under refluxing conditions. Freshly prepared stannic hydroxide gel is allowed to crystallize under refluxing and stirring conditions for 4-6 h. Formation of nano crystallites of $\mathrm{SnO}_{2}$ is confirmed by $\mathrm{X}$ ray diffraction (XRD) study. Transmission electron microscopic (TEM) investigations revealed that the average particle size is $30 \mathrm{~nm}$ for these powders.
\end{abstract}

Keywords. Ceramics; oxides; chemical synthesis; $\mathrm{SnO}_{2}$; $\mathrm{X}$-ray diffraction.

\section{Introduction}

Tin (IV) oxide has been a widely studied material over decades because of its wide range of applications as gas sensors, heat mirrors, transparent electrodes for solar cells, opto-electronic devices and in catalysis (Romppainen et al 1990; Coles et al 1991; Maekawa et al 1992). Tin dioxide is a $n$-type semiconductor crystallizing in tetragonal rutile structure. The unit cell parameters are $a=4.737 \mathrm{~A}$ and $c=$ $3.185 \mathrm{~A}$ and its space group is $P 4_{2} / \mathrm{mmm}$. It is very difficult to sinter $\mathrm{SnO}_{2}$ to high densities without additives due to condensation-evaporation mechanism operating during sintering. This property is exploited in the gas and humidity sensing applications (Fagan and Amarakoon 1993). Recently varistor characteristics were also reported (Ravi and Date 2001; Dhage et al 2002; Dhage and Ravi 2003) in dense doped $\mathrm{SnO}_{2}$. To prepare active nanocrystalline powders, several chemical techniques have been investigated and reported in the literature. Among the various methods of preparing nanostructured $\mathrm{SnO}_{2}$, co-precipitation, sol-gel, spray pyrolysis, hydrothermal routes, freezedrying, etc are popular. Recently, gel combustion routes using a variety of organic fuels like urea, hydrazine, citric acid and others have been reported to be promising methods to prepare a variety of oxides including nanocrystalline $\mathrm{SnO}_{2}$ (Bhagwat et al 2003). Though the combustion methods are fairly simple, higher calcination temperatures have been reported and the method requires an oxidizing agent and necessarily a fuel in the reaction mixture (Bhagwat et al 2003). The method of gel to crystalline conversion is reported in the literature for the preparation of multicomponent oxides such as perovskites and spinels (Padmini and Kutty 1994; Kutty and Padmini 1995). But this method is not yet reported for the preparation of $\mathrm{SnO}_{2}$

*Author for correspondence ceramics. Here, we report this simple process of digestion of amorphous stannic hydroxide gel under refluxing conditions at $100^{\circ} \mathrm{C}$ for the preparation of nanocrystalline $\mathrm{SnO}_{2}$.

\section{Experimental}

$\mathrm{SnCl}_{4}$ was diluted with ice-cold distilled water to form $\mathrm{SnOCl}_{2}$ solution. To this solution ammonium hydroxide was added dropwise to precipitate tin as hydroxide. The hydrated stannic hydroxide gel was thoroughly washed free of anions and transferred to flask fitted with a water condenser. The gel was continuously stirred for $6 \mathrm{~h}$ and temperature was maintained around $70-100^{\circ} \mathrm{C}$. The solid mass after refluxing was found to be crystalline and free flowing. Then the crystalline powder formed was filtered and oven dried. Various techniques such as XRD (Philips PW 1710 Diffractometer), and BET surface area measurements (Nova 1200 instrument) were employed to characterize these powders. For comparison, freshly prepared tin hydroxide precipitate was decomposed at various temperatures between 200 and $500^{\circ} \mathrm{C}$ for $12 \mathrm{~h}$. For lattice parameter and interplanar distance $(d)$ calculation, the samples were scanned in the $2 \theta$ range of $10^{\circ}-80^{\circ}$ for $5 \mathrm{~s}$ in the step scan mode. Silicon was used as an internal standard. Least squares method was employed to determine the lattice parameters. The TEM picture was recorded with JEOL model 1200 EX instrument at the accelerating voltage of $100 \mathrm{kV}$. The fine powders were dispersed in amyl acetate on a carbon coated TEM copper grid.

\section{Results and discussion}

Figure 1 shows the XRD for the samples before and after refluxing at $100^{\circ} \mathrm{C}$. The sample is $\mathrm{X}$-ray amorphous for the former and no distinct peaks are observed. The powders 


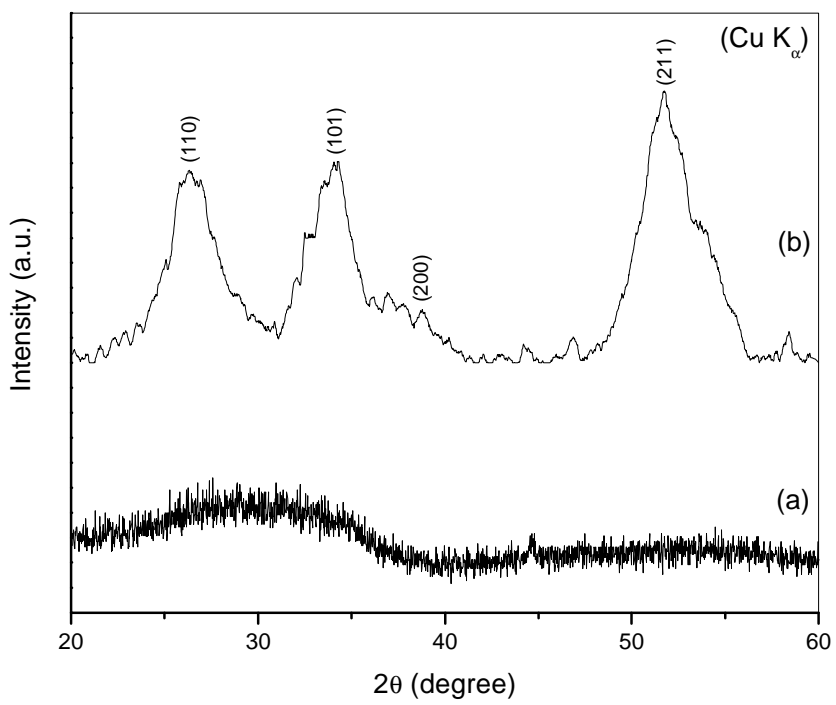

Figure 1. XRD of (a) freshly prepared tin hydroxide precipitate before refluxing and (b) after refluxing for $4 \mathrm{~h}$ at $100^{\circ} \mathrm{C}$.

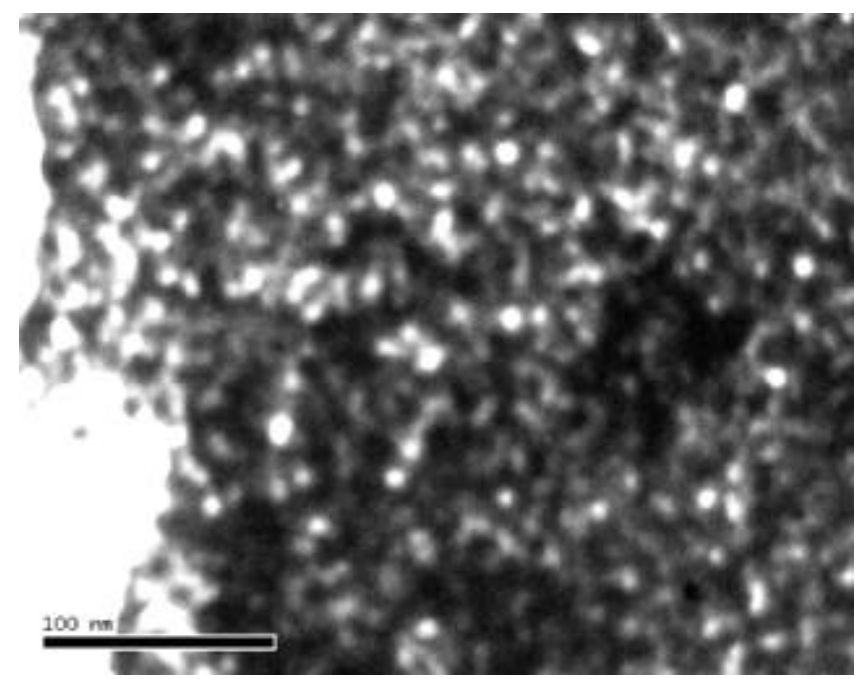

Figure 2. TEM micrograph of tin dioxide powders prepared at $100^{\circ} \mathrm{C}$.

after digestion showed the crystalline pattern and the observed $d$-lines match the reported values for the rutile $\mathrm{SnO}_{2}$ phase. The calculated lattice parameters are $a=4.738 \AA$ and $c=3 \cdot 188 \AA$. It is to be noted that the molarity of the solution should be $>0 \cdot 15 \mathrm{M}$ of $\mathrm{SnO}_{2}$ to obtain crystallization in this process. Otherwise it requires long durations to form a crystalline product at $100^{\circ} \mathrm{C}$. It is to be noted that crystalline $\mathrm{SnO}_{2}$ is found to be formed from the hydroxide precipitate without refluxing, when calcined at $400^{\circ} \mathrm{C}$ for $12 \mathrm{~h}$. This shows the advantage of the present method. The average particle size is found to be $30 \mathrm{~nm}$ and the particles are observed to be agglomerated (figure 2). The surface area of the these powders was found to be $70 \mathrm{~m}^{2} / \mathrm{g}$. The crystallite size measurements were also carried out using the Scherrer equation, $D=k \lambda / \beta \cos \theta$, where $D$ is the crystallite size, $k$ a constant $(=0.9$ assuming that the particles are spherical), $\lambda$ the wavelength of $X$-ray radiation, $\beta$ the line width (obtained after correction for the instrumental broadening) and $\theta$ the angle of diffraction. The average particle size obtained from XRD data is $40 \mathrm{~nm}$. Metal hydroxide gels are in general polymeric chains forming an entangled network in which solvent is entrapped. It is the osmotic pressure, which is the sum of rubber elasticity, polymer-polymer affinity and hydrogen ion pressure that contributes to stability of the gel. If any one of the factors is altered, the gel collapses irreversibly. The continuous influx of solvent breaks the gel network and small crystalline regions are created. This crystallization is favoured because of reduction in the free energy. Thus possibly $\mathrm{SnO}_{2}$ phase is formed at $100^{\circ} \mathrm{C}$. These fine powders obtained by this simple gel to crystalline method are potential candidates for gas sensors and varistor applications.

\section{Conclusion}

Nanocrystalline tin dioxide powders are obtained at $100^{\circ} \mathrm{C}$ with the average particle size $\sim 30 \mathrm{~nm}$ by refluxing hydrated tin hydroxide precipitate for $4 \mathrm{~h}$.

\section{Acknowledgement}

The authors are thankful to the Department of Science and Technology, New Delhi, for financial support (grant no. SP/S1/H-19/2000).

\section{References}

Bhagwat M, Shah P and Ramaswamy V 2003 Mater. Lett. 57 1604

Coles G S V, Williams G and Smith B 1991 J. Phys., D, Appl. Phys. 24633

Dhage S R and Ravi V 2003 Appl. Phys. Lett. 834539

Dhage S R, Ravi V and Date S K 2002 Mater. Lett. 57727

Fagan J G and Amarakoon 1993 Am. Ceram. Soc. Bull. 72119

Kutty T R N and Padmini P 1995 Mater. Chem. \& Phys. 39200

Maekawa T, Tamaki J, Miura N, Yamazoe N and Matasushima S 1992 Sensors \& Actuators B9 63

Padmini P and Kutty T R N 1994 J. Mater. Chem. 41875

Ravi V and Date S K 2001 Bull. Mater. Sci. 24483

Romppainen P, Lantto V and Leppavuori S 1990 Sensors \& Actuators $\mathbf{B} 173$ 